\title{
Normal levels of serum pancreatic enzymes in patients with progressive familial intrahepatic cholestasis type $\mathbf{2}$
}

\author{
Jaroslaw Walkowiak ${ }^{1,2}$, Irena Jankowska ${ }^{3}$, Aleksandra Lisowska1', Maciej Biczysko ${ }^{4}$, \\ Aldona Wierzbicka ${ }^{5}$ and Joanna Pawłowska ${ }^{3}$ \\ 1Poznań University of Medical Sciences, Department of Pediatric Gastroenterology and Metabolism, Poznań, Poland; 2University of Life Sciences, \\ Chair of Human Nutrition and Hygiene, Department of Dietetics, Poznań, Poland; ${ }^{3 T h e}$ Children's Memorial Health Institute, Department of \\ Gastroenterology, Hepatology and Immunology, Warszawa, Poland; 4Poznań University of Medical Sciences, Chair of General, Gastroenterologi- \\ cal and Endocrinological Surgery, Poznań, Poland; ${ }^{5}$ The Children's Memorial Health Institute, Department of Biochemistry and Experimental \\ Medicine, Warszawa, Poland
}

Introduction. High prevalence of elevated serum pancreatic enzymes in children with cholestasis with normal fecal elastase-1 concentrations has been documented. However, this state is related predominantly to biliary atresia. Therefore, we aimed to assess pancreatic damage by measuring serum pancreatic enzymes in patients with progressive familial intrahepatic cholestasis type 2 (PFIC type 2). Materials and methods. Twenty PFIC type 2 patients with normal serum bilirubin and bile acid concentrations were included in the study. Thirty pancreatic insufficient cystic fibrosis (PI-CF) patients, thirty patients with acute pancreatitis (AP) and thirty healthy subjects (HS) served for the purpose of comparison. In all subjects, serum lipase and elastase-1 levels were measured. Results. In all but one PFIC type 2 patients and all HS normal lipase activities were found. Serum elastase- 1 concentrations were normal in all PFIC type 2 patients and HS. The enzyme levels were very similar in both groups studied. Lipase activities in PFIC type 2 patients were significantly higher than in PI-CF patients $(P<0.00001)$ and lower than in patients with AP $(P<0.00001)$. Serum elastase-1 levels in PFIC type 2 patients were significantly lower than in patients with AP $(P<0.00001)$ and not different from those in PI-CF patients. In conclusion. serum pancreatic enzymes in patients with PFIC type 2 are normal. No pancreatic damage in these patients could be detected.

Keywords: progressive familial intrahepatic cholestasis type 2, pancreatitis, pancreatic enzymes, lipase, elastase- 1

Received: 14 July, 2010; revised: 07 October, 2010; accepted: 03 November, 2010; available on-line: 06 December, 2010

\section{INTRODUCTION}

Progressive familial intrahepatic cholestasis type 2 (PFIC type 2) results from genetic defects of the hepatobiliary bile salt export pump (BSEP) encoded by the $A B C B 11$ gene at chromosome $2 \mathrm{q} 24$. The diagnosis of PFIC type 2 should be always suspected in patients with neonatal or post-neonatal cholestasis, low/normal GGT and severe pruritus. Pruritus is usually the predominant symptom and skin excoriations due to itching may be observed. Other clinical symptoms include hepatosplenomegaly and failure to thrive. The disease may progress to end stage liver disease. Medical therapy is ineffective in PFIC and only $10 \%$ of the patients show clinical and laboratory improvement after UDCA therapy. Some experience points to a successful therapy with partial external biliary diversion or ileal bypass when performed early in the course of the disease. Liver transplantation is the only curative option for PFIC patients who failed to respond positively to other therapy (Strautnieks et al., 2008).

Steatorrhea is frequent in patients with PFIC type 2 and disturbances of bile salt secretion are a reasonable explanation for this finding. However, impaired exocrine pancreatic function could also be an underlying factor. Recently we have proved that pancreatic exocrine secretion in patients with PFIC type 2 is normal. With the use of three different indirect tests (fecal elastase-1, chymotrypsin and lipase) we demonstrated conclusively that steatorrhea observed at diagnosis in 14 children was not related to pancreatic dysfunction (Walkowiak et al., 2006).

Wen and coworkers (2005) documented high prevalence of elevated serum pancreatic enzymes in children with cholestasis with normal fecal elastase-1 concentrations. Hyperamylasemia and hyperlipasemia were found in $7(19 \%)$ and $12(32 \%)$ of 37 studied subjects. A decreased hepatic metabolism was suggested as an underlying factor. However, only one patient with PFIC type 2 was studied. In the present study we aimed to assess potential pancreatic damage by measuring serum pancreatic enzymes in PFIC type 2 patients.

\section{MATERIALS AND METHODS}

Twenty patients ( 8 girls and 12 boys) aged 5 to 24 years (median: 10 ; mean \pm S.E.M.: $12.2 \pm 1.1$ ) with the diagnosis of BSEP deficiency were included in the study. Study protocol was approved by the Ethics Committee of the Memorial Child Health Institute (Warszawa, Poland). The diagnosis was based on history, clinical presentation and typical biochemical parameters, and confirmed by molecular analysis of the $A B C B 11$ gene. Respectively fourteen and two subjects underwent biliary diversion and ileal bypass. Four subjects were treated exclusively with ursodeoxycholic acid. Fecal fat excretion was differentiated and ranged from 0.3 to $23.4 \mathrm{~g} /$ day (median: $4.3 \mathrm{~g} / \mathrm{day}$ ).

e-mail: jarwalk@am.poznan.pl

Abbreviations: BSEP, bile salt export pump; PFIC, progressive familial intrahepatic cholestasis; PI-CF, pancreatic insufficient cyclic fibrosis; UDCA, ursodeoxycholic acid 


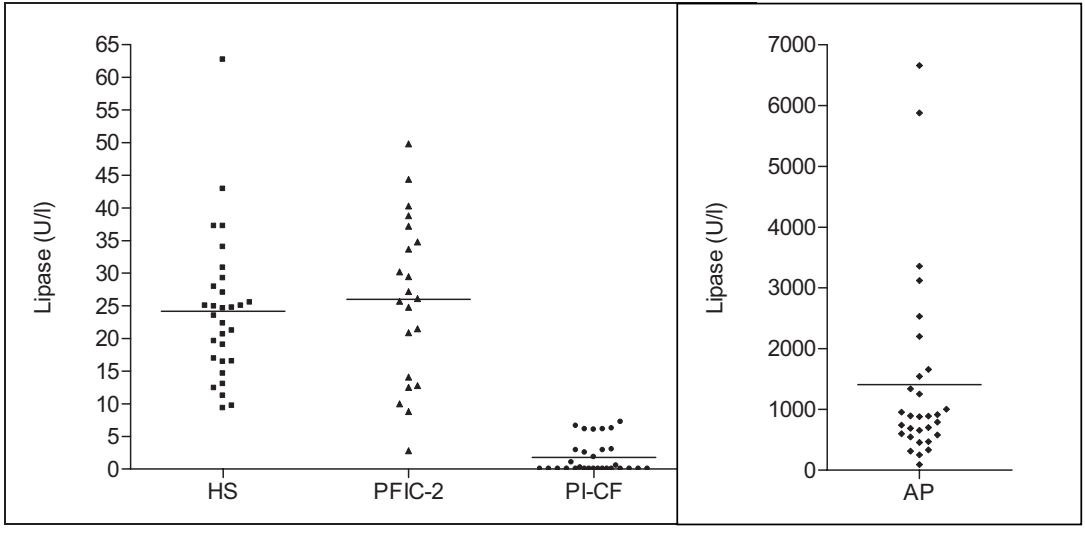

Figure 1. Distribution of serum lipase activities in patients with progressive familial intrahepatic cholestasis type 2 (PFIC-2), acute pancreatitis (AP), pancreatic insufficiency with cystic fibrosis (PI-CF) and healthy subjects (HS).

Inclusion criteria comprised willingness to participate in the study, age 12 months and older, cessation of cholestasis - normal serum bilirubin $(<20 \mu \mathrm{mol} / \mathrm{l})$ and bile acids $(<12 \mu \mathrm{mol} / \mathrm{l})$ concentrations after conservative (oral ursodeoxycholic acid $(30 \mathrm{mg} / \mathrm{kg}$ per day) or surgical treatment (biliary diversion or ileal bypass), whereas exclusion criteria - an acute episode of diarrhea before or during the study.

Thirty pancreatic insufficient cystic fibrosis (PI-CF) patients aged 5 to 16 years (median: 12; mean \pm S.E.M.: $11.6 \pm 0.5$ ) with severe exocrine pancreatic insufficiency (steatorrhea), thirty patients with acute pancreatitis aged 7 to 25 years (median: 20 ; mean \pm S.E.M.: $17.5 \pm 0.9$ ) and thirty healthy subjects aged 18 to 22 years (median: 20; mean \pm S.E.M.: $20.1 \pm 0.2$ ) served for the purpose of comparison.

In all subjects two pancreatic enzymes were measured. Serum lipase was measured with the use of a colorimetric method (Roche Diagnostics GmbH, Mannheim, Germany) (Imamura et al., 1989) and serum elastase-1 using an immunoenzymatic method (ScheBo Biotech AG, Germany) (Walkowiak et al., 2005). Lipase activities in the range of $10-66 \mathrm{U} / \mathrm{ml}$ and elastase-1 levels below $3.5 \mathrm{ng} / \mathrm{ml}$ were considered to be normal.

The statistical differences between patients with PFIC type 2 and other groups (healthy subjects, PI-CF patients and subjects with acute pancreatitis), as well as between selected subgroups of PFIC type 2 patients (with and without steatorrhea), were calculated with the use of the Mann-Whitney $U$ test. The level of significance was set at $P<0.05$.

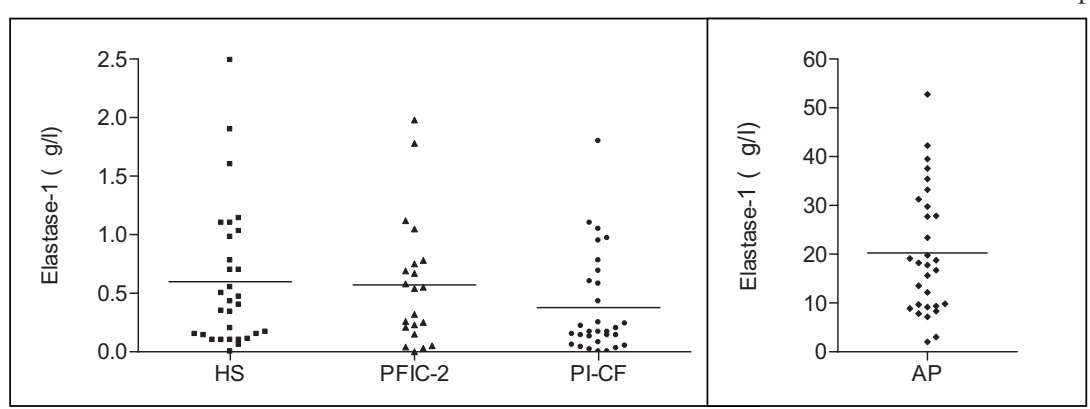

Figure 2. Distribution of serum elastase-1 concentrations in patients with progressive intrahepatic cholestasis type 2, acute pancreatitis, cystic fibrosis with pancreatic insufficiency and healthy subjects.

For abbreviations see Fig. 1.

\section{RESULTS}

The distribution of serum enzymes in the subjects studied is presented in Figs. 1 and 2 and summarized in Tables 1 and 2 .

Abnormal (high) serum lipase activities were present in all subjects with acute pancreatitis. In 28 $(93.3 \%)$ CF patients very low lipase activities were found (beyond the detection limit). However, in the remaining two $\mathrm{CF}$ subjects low (10 and $11 \mathrm{U} / \mathrm{l})$, although normal, lipase levels were detected. In all but one PFIC type 2 patients and all healthy subjects normal lipase activities were present. Serum elastase-1 concentrations were normal in all PI-CF patients, PFIC type 2 patients and healthy subjects. Abnormal values were found in $28(93.3 \%)$ of patients with acute pancreatitis.

Serum lipase activities in PFIC type 2 patients were significantly higher than in PI-CF patients $(P<0.00001)$ and lower than in patients with mild acute pancreatitis $(P<0.00001)$. They did not differ from values obtained in healthy subjects. Serum elastase-1 concentrations in PFIC type 2 patients were not different from those in PI-CF patients and healthy subjects. However, the enzyme levels were significantly higher in patients with mild acute pancreatitis $(P<0.00001)$.

No differences in serum pancreatic enzyme concentrations/activities between subgroups of subjects with PFIC type 2 with or without steatorrhea were noted. No correlation between fecal fat excretion and serum lipase and elastase-1 levels was detected.

\section{DISCUSSION}

In the present study, we have demonstrated that the levels of selected serum pancreatic enzymes in PFIC type 2 patients are not different from those in healthy subjects. For the purpose of the assessment we selected lipase and elastase-1, which were proved to have high sensitivity and specificity among serum tests for the assessment of pancreatic damage. The results obtained in PFIC type 2 patients were clearly different from those of patients with chronic and acute pancreatitis (Figs. 1 and 2). Patients with cystic fibrosis, the most frequent form of chronic pancreatitis in childhood with pancreatic tissue damage (Walkowiak, 2004), comprised one comparative group. As it could be expected according to its pathophysiology serum lipase and elastase- 1 levels were low (Millson et al., 1998). On the other hand, we selected a group of patients with a mild form (oedomatous) of acute pancreatitis. Abnormal results (high concentrations) were documented in all studied subjects (Wilson et al., 2005; Lieb \& Draganov, 2008). The levels of serum pancreatic enzymes in PFIC type 2 patients were practically identical to those observed in 
Table 1 Serum lipase activities in patients with PFIC type 2, pancreatic insufficiency with cystic fibrosis, acute pancreatitis and in healthy subjects

\begin{tabular}{|c|c|c|c|c|}
\hline \multirow{2}{*}{ Lipase activity (U/I) } & \multicolumn{4}{|c|}{ Subject group } \\
\hline & PFIC type 2 & $\mathrm{PI}-\mathrm{CF}$ & AP & $\mathrm{HS}$ \\
\hline Mean \pm S.E.M. & $26.0 \pm 2.3$ & $1.8 \pm 0.5$ & $1409 \pm 282$ & $24.2 \pm 2.0$ \\
\hline Median & 26.1 & 0 & 884 & 24.1 \\
\hline Range & $2.8-49.8$ & $0-7.2$ & $90-6657$ & $9.3-62.7$ \\
\hline 1 st -3 rd quartile & $14.1-34.8$ & $0-2.9$ & $583-1491$ & $16.6-27.7$ \\
\hline
\end{tabular}

Normal range: $10-66 \mathrm{U} / \mathrm{I}$

Table 2 Serum elastase-1 concentrations in patients with PFIC type 2, pancreatic insufficiency with cystic fibrosis, acute pancreatitis and in healthy subjects

\begin{tabular}{|c|c|c|c|c|}
\hline \multirow{2}{*}{ Elastase-1 concentrations (mg/l) } & \multicolumn{4}{|c|}{ Subject group } \\
\hline & PFIC type 2 & $\mathrm{PI}-\mathrm{CF}$ & AP & HS \\
\hline Mean \pm S.E.M. & $0.57 \pm 0.12$ & $0.38 \pm 0.08$ & $20.26 \pm 2.35$ & $0.60 \pm 0.11$ \\
\hline Median & 0.54 & 0.17 & 18.01 & 0.42 \\
\hline Range & $0-1.98$ & $0-1.80$ & $2.01-52.80$ & $0-2.49$ \\
\hline 1st-3rd quartile & $0.21-0.75$ & $0.09-0.60$ & $9.5-29.3$ & $0.14-0.93$ \\
\hline
\end{tabular}

Normal range: $<3.5 \mu \mathrm{g} / \mathrm{l}$

healthy subjects. Moreover, we did not observe any dependence of serum lipase and elastase-1 levels on fecal fat excretion.

Steatorrhea is a frequent finding in cholestatic pediatric patients. Bile salt disturbances are a reasonable explanation for this finding. However, diminished exocrine pancreatic secretion could also be an underlying or contributing factor. Recently, we have clearly demonstrated that pancreatic secretion in PFIC type 2 patients as measured by fecal indirect test is normal (Walkowiak et al., 2006). However, this does not preclude damage of the pancreatic tissue. Wen and co-workers (2005) proved that in a significant percentage of cholestatic children elevated levels of pancreatic enzymes are present. However, only one PFIC type 2 subject was studied, presenting normal amylase and lipase activities. Therefore, in the present study we studied a large cohort of PFIC type 2 patients without cholestasis documenting normal serum levels of pancreatic enzymes - in one subject only lipase activity was found to be abnormal (low). Abdominal ultrasonography routinely performed several times in every subject did not reveal any pancreatic abnormality. It seems that the Wen and co-workers finding is related predominantly to biliary atresia and has nothing to do with PFIC type 2 . Lipase and elastase-1 measurements have a high, although not perfect sensitivity in the diagnosis of acute pancreatitis (Millson et al., 1998; Yadav et al., 2002). Therefore, their diagnostic value in the detection of mild pancreatic involvement might be lower and we cannot exclude mild pancreatic damage in single cases. With this reservation in mind, the elevation of serum pancreatic enzymes definitely is not a specific feature of PFIC type 2 .

In conclusion, serum levels of pancreatic enzymes in patients with progressive familial intrahepatic cholestasis type 2 are normal. No pancreatic damage in these patients could be detected.

\section{Acknowledgements}

The project was supported by the University of Medical Sciences in Poznań (502-01-1103603-07588).

Molecular analysis of $A B C B 11$ genes was performed by Sandra Strautnieks and Richard Thompson, in the Institute of Liver Studies, King's College London, United Kingdom.

\section{REFERENCES}

Imamura S, Hirayama T, Arai T, Takao K, Misaki H (1989) An enzymatic method using 1,2-diglyceride for pancreatic lipase test in serum. Clin Chem 35: 1126.

Lieb JG 2nd, Draganov PV (2008) Pancreas function testing: here to stay for the 21st century. World J Gastroenterol 28: 3149-3158.

Millson CE, Charles K, Poon P, Macfie J, Mitchell CJ (1998) A prospective study of serum pancreatic elastase- 1 in the diagnosis and assessment of acute pancreatitis. Scand J Gastroenterol 33: 664-668.

Strautnieks SS, Byrne JA, Pawlikowska L, Cebecauerová D, Rayner A, Dutton L, Meier Y, Antoniou A, Stieger B, Arnell H, Ozçay F, AlHussaini HF, Bassas AF, Verkade HJ, Fischler B, Németh A, Kotalová R, Shneider BL, Cielecka-Kuszyk J, McClean P, Whitington PF, Sokal E, Jirsa M, Wali SH, Jankowska I, Pawłowska J, MieliVergani G, Knisely AS, Bull LN, Thompson RJ (2008) Severe bile salt export pump deficiency: 82 different $A B C B 11$ mutations in 109 families. Gastroenterology 134: 1203-1214.

Walkowiak J (2004) Assessment of maldigestion in cystic fibrosis. I Pediatr 145: 285-287.

Walkowiak J, Nousia-Arvanitakis S, Henker J, Stern M, Sinaasappel M, Dodge JA (2005) Indirect pancreatic function tests in children. J Pediatr Gastroenterol Nutr 40: 107-114.

Walkowiak J, Jankowska I, Pawłowska J, Strautniesk S, Bull L, Thompson R, Herzig KH, Socha J (2006) Exocrine pancreatic function in children with progressive familial intrahepatic cholestasis. I Pediatr Gastroenterol Nutr 42: 416-418.

Wen WH, Chen HL, Chang MH, Ni YH, Shih HH, Lai HS, Hsu WM (2005) Fecal elastase 1, serum amylase and lipase levels in children with cholestasis. Pancreatology 5: 432-437.

Wilson RB, Warusavitarne J, Crameri DM, Alvaro F, Davies DJ, Merrett $N$ (2005) Serum elastase in the diagnosis of acute pancreatitis: a prospective study. ANZ J Surg 75: 152-156.

Yadav D, Agarval N, Pitchumoni CS (2002) A critical evaluation of laboratory tests in acute pancreatitis. Am J Gastroenterol 97: 1309_ 1318. 